anthropology \& materialism

\section{Anthropology \& Materialism}

A Journal of Social Research

Special Issue | I | 2017

Discontinuous Infinities

\title{
Towards a Benjaminian Critique of Hermann Cohen's Logical Idealism
}

\section{Phillip Homburg}

\section{Q OpenEdition}

\section{Journals}

\section{Electronic version}

URL: http://journals.openedition.org/am/742

DOI: $10.4000 / a m .742$

ISSN: 2364-0480

\section{Publisher:}

CETCOPRA, CRASSH - Center for Research in the Arts Social Sciences and Humanities, Fakultät

Gestaltung - Universität der Künste Berlin

\section{Electronic reference}

Phillip Homburg, «Towards a Benjaminian Critique of Hermann Cohen's Logical Idealism »,

Anthropology \& Materialism [Online], Special Issue | I | 2017, Online since 02 March 2017, connection on 01 May 2019. URL : http://journals.openedition.org/am/742 ; DOI : 10.4000/am.742

This text was automatically generated on 1 May 2019.

Tous droits réservés 


\title{
Towards a Benjaminian Critique of Hermann Cohen's Logical Idealism
}

\author{
Phillip Homburg
}

\section{Introduction}

1 In the text, "On the Program of the Coming Philosophy" (1918), Walter Benjamin frames his investigation into the philosophies of Kant and neo-Kantianism in a two-fold manner: "First of all, there was the question of the certainty of knowledge that is lasting, and, second, there was the question of the dignity [Dignität] of an experience that is ephemeral". ${ }^{1}$ In this article I will take this as the problem of neo-Kantianism, for Benjamin. This is the problem of the establishment of continuity between objective knowledge and so-called ephemeral experience, i.e. a form of experience that is fragmentary and subjective. As I will show, for Benjamin, Kant was only able to give an answer to the first problem since his aim was to secure the timeless validity and certainty of cognition. In regards to neo-Kantianism, in order to secure the integrity of cognition from the ephemeral nature of experience, their concepts had to be purified of any content taken from sensible perception. The price neo-Kantianism paid for the dignity and integrity of its epistemological standpoint was the subordination of empirical experience to a transcendent conception of pure thought and a strictly logical method. Accordingly, the aim of this article is to clarify Benjamin's relationship to neo-Kantianism and to provide the grounds for a Benjaminian critique of neo-Kantianism.

2 This piece will be divided into two parts. First, I will examine the neo-Kantianism of Hermann Cohen. I will focus on Cohen's logical and scientific form of idealism, in particular its critique of Lange's subjective idealism, on the one hand, and empiricism, on the other. Finally, I will look at Benjamin's engagement with neo-Kantianism, specifically in "On the Program of the Coming Philosophy" and the short fragment "On Perception" (1917) that precedes it. 


\section{Hermann Cohen's Logical Idealism}

3 Hermann Cohen's neo-Kantianism exists in a relationship to the form of neo-Kantianism that preceded it, specifically the early neo-Kantianism of Hermann von Helmholtz and Friedrich Albert Lange. Helmholtz and Lange defended Kantianism against the philosophical standpoint known as scientific materialism. Put very briefly, scientific materialism held, against Kant, that the senses were the only instruments capable of objective knowledge of reality:

There is no visible reason whatever why nature should deceive man ... We may take a photograph of an object, a rose, for instance. It would be impossible for this photograph to evoke the same presentation in our brain as the original, if the presentation was not a fairly correct interpreter of reality. ${ }^{2}$

4 Helmholtz took issue with the empiricism characteristic of scientific materialism and held that sensation produced "signs [Zeichen] of the objects of the external world, and correspond[s] to them only in some such way as written characters or articulate words to the things they denote". ${ }^{3}$ Helmholtz takes the precise opposite position to that of the scientific materialists: the image of an object is analogous to the original. Sensation offers a representation (or Abbild) of an object, but does not provide a direct copy (or Bild) of it.

5 For his part, Lange deepens Helmholtz' critique of empiricism in his distinction between reality and the ideal. For Lange, as for Helmholtz, the sense organs are organs of abstraction, not truth. They can only lead to what is relatively true. ${ }^{4}$ For Lange, materialism points to what the idealist already knows: that knowledge, even sense knowledge, is a product of human organisation. Materialism, the lowest and firmest stage in philosophy, should be restricted to the empirical, while idealism should deal with the loftier aspects of human reason. Ideas are products of human organisation that are "grounded in the natural disposition of mankind and possess a practical purpose". ${ }^{5}$ Lange offers what he refers to as the standpoint of the ideal, which is creative and aesthetic in character. The danger of the ideal is that materialism can destroy it as long as it is inexorably entwined with religious thought. Only by removing the core of religion in the process of elevating the soul above reality can idealism ensure its safety from materialist criticism. ${ }^{6}$ Lange claims that we must separate the idea "from any correspondence with historical and scientific knowledge, but also without falsification of them, let us accustom ourselves to regard the world of ideas as figurative representation of the entire truth, as just as indispensable to human progress as the knowledge of the understanding". ${ }^{7}$ The strict separation between reality and the ideal is central to Lange's standpoint in order to maintain the integrity of the ideal from the mechanistic worldview of the scientific materialists. At the same time, in viewing the ideal as purely figurative and external to reality, Lange inserts an ontological gap between the objectivity of the empirical world governed by the mechanistic forces described by scientific materialism - and a free, spontaneous ideal that can only exist in contradistinction to reality. I will now move onto Cohen, beginning with his critique of Lange's standpoint of the ideal.

6 For Cohen, Lange's distinction between materialism and idealism was superficial. In renouncing idealism's claim to knowledge of reality, Lange is forced to accept an empiricist theory of knowledge: knowledge must be restricted to what can be verified in experience. By reading Kant's deduction of the categories psycho-physically, Lange believed that he could legitimately claim to have overcome the gap between the 
transcendental and empirical in Kant's thought. For Cohen, this led to an inability on Lange's part to locate his practical philosophy within the theoretical. This not only raises a problem for practical philosophy, but for theoretical philosophy as well. Lange, Cohen claims, treats the idea as "an inner emotional concept" rather than as an "epistemological emblem". ${ }^{8}$ As a result of his naturalisation of the idea and his abandonment of ethics to the transcendent realm of the idea, Lange fundamentally misunderstood the nature of idealism. In contrast to Lange, Cohen aimed to assign ethics a status that raises it to the same level of dignity as the concepts of logic or mathematics. In doing so, he goes further than Lange in conceiving of the ethical idea as something that totally exceeds experience yet, at the same time, forms its fundamental basis. In Cohen's words: "If all reality of experience, if all sensible existence were destroyed, its boundaries in the noumenon would have to remain. If all nature were to perish, the Idea of freedom would remain. If all experience should cease, ethical reality would remain". 9

7 Against Lange's subjective ideal, as I will show, Cohen understands the ethical idea as a hypothesis that underlies empirical reality in pure thought. For Cohen, pure thought or reason cannot merely be a product of sensation. In turn, reality cannot be reduced to what can be sensibly intuited. As Cohen states in the Religion of Reason (1919): "The senses are in direct opposition to reason; basically they are common to animals and men". ${ }^{10} \mathrm{In}$ his logical and systematic approach, Cohen places his emphasis on critical idealism's role in providing an epistemological foundation not only for ethics but also for all domains of inquiry into the nature of reality. Central to this project is a conception of the idea as hypothesis. Cohen places his conception of pure thought - thought that produces content by itself - against notions of representational thinking. According to Cohen's reading of Kant, the factual validity of mathematical principles is presupposed and these principles are seen as pure because they are self-evident and non-derivable from empirical experience. ${ }^{11}$ For Cohen, mathematics is a model for pure thought insofar as it is nonrepresentational; real knowledge is pure thought free from sensuous representation. Ideas as hypotheses both precede and ground being. As hypotheses, ideas provide the objective grounding for forms of representational thinking which follow.

The result of this conception of the relationship between conceptual science and reality is, for Cohen, the re-establishment of the link between both theoretical and practical philosophy, on the one hand, and speculative philosophical thought and scientific inquiry into the empirical world, on the other. However, by rejecting the subjectivist reading of Kant, Cohen subtly shifts the ground of Kant's critique. In order to become scientifically valid, experience comes to be identified with scientific cognition. For Cohen, philosophy does not take science's place, but as a form of critique it takes the 'fact' of science as its starting point. The aim of critical idealism differs from science in that it is the transcendental investigation into the possibility of nature as an object of scientific inquiry as such. Cohen is able to assert that the progress of critical philosophy plays a foundational role in principles that underlie natural science. Cohen, therefore, follows Lange's privileging of thought over reality: "pure thought as the method for the foundation of reality". ${ }^{12}$ As such, critical philosophy is best placed to investigate the grounds of science's claim to knowledge of reality. This is the meaning of the neo-Kantian program of epistemological critique: that philosophy provides a critical theory of knowledge that is able to reflect on both its own and science's methodological presuppositions.

For Cohen, any theory of the subject must wrestle with the fact that an empirical or psychological subject is not the subject of valid knowledge, but of error. The objectivity 
and validity of knowledge must, therefore, be posited at the level of a transcendental logic that exceeds the empirical psychological subject. Cohen marks a distinction between an empirical subject who is the subject of error, and the form of transcendental logic that exceeds both the empirical subject and reality itself. Critical idealism asserts a logicaltranscendental subject that acts as the normative principle and grounds for a form of judgement that is free from error. With this, Cohen is able to overcome the distinction between materialism and idealism that Lange could only achieve by assigning the two standpoints to their respective theoretical corners. Against Lange's dualism, Cohen is able to reconcile the two standpoints immanently in pure thought. Materialism's absolute whether it is matter, the atom, or nature - only gains its objective reality as a product of pure thought. The application of a concept of pure thought to empirical reality and the objective knowledge that this application provides can only be justified critically in reference to the concept's origin. It is this notion of origin that is central to Cohen's critical idealism. Through his concept of origin, Cohen is able to posit a transcendental unity of consciousness that exists in pure thought prior to any distinction between subject and object. For Cohen, there is a logical origin [Ursprung] prior to any form of judgement based on the distinction between thought and being.

Inherent in Cohen's conception of rational origin, therefore, is a rejection of the Kantian separation of the spontaneous faculty of the understanding and a receptive faculty of sensibility. Cohen remains within the Kantian problematic in relation to the limits of possible experience, in particular the limit of empirical or sense experience. However, he separates his logic of origin from any form of philosophy that begins from a logic of being, a standpoint that Cohen claims characterized romanticism. ${ }^{13}$ In Cohen's logic of origin, being or existence is subordinated to pure thought. Cohen's claim is that the logic of origin is the foundation of modern science and, therefore, his form of idealism. Origin is a principle for Cohen in two senses of the word: first, it is the supreme principle of pure knowledge from which every content originates and is grounded; second, pure thought as the thought of origin produces both the object of knowledge and grounds that object in thought.

11 For Cohen, "[o]nly thought itself can produce what can count as being". ${ }^{14}$ In terms of the first point, the aim of knowledge is a process of verification by which it can verify objects of knowledge as products of pure thought. ${ }^{15}$ In terms of the second, Cohen's conception of pure thought requires that nothing be given to thought prior to its determinations. In other words, to the extent that it is productive, pure thought must be able to situate its object of knowledge within itself prior to any a posteriori determinations. Pure thought does not presuppose a given reality or object which presents itself to thought externally through the forms of sensible intuition. Kant's "Anticipations of Perception" demonstrates how appearance manifests itself in sensible intuition. There is, for Kant, a sense in which the object must have a substantial reality in order for it to appear as object for determination by the understanding. For Cohen, by contrast, the givenness of the object is not an issue; the determination of reality is consigned solely to the spontaneous and productive understanding. Empirical reality, as an apparently independent object of knowledge standing over and against pure thought, is conceived as an incomplete object to which the epistemological method of the mathematical sciences is successively and continually applied. The object of scientific knowledge, given to thought through the forms of sensible intuition, can be said to exist merely as a 'not yet' conceptualized point on which the methods of mathematical and natural science are progressively converging. 

moment in the process of the progressive methodological development of the natural sciences. While Cohen acknowledges the importance of the forms of intuition for Kant, he is also, at the same time, able to undermine their centrality within the Kantian system. In other words, for Cohen, Kant quite correctly began from the highest point of scientific development available to him, but that moment has since been subordinated in the movement of scientific progress. The validity of the forms of intuition as principles of science must be acknowledged, but they were not Kant's central contribution to philosophy. Rather, for Cohen, Kant's significance is found in his general methodological starting point: the basic 'fact' of pure mathematical science, rather than the application of any particular scientific principles. For Cohen, the reality intuited through Kant's forms is not something that exists over and against the concepts of natural science as a 'thing' to be deciphered. Rather, reality is only constituted as an object of knowledge through its subordination to pure, meta-empirical scientific concepts. ${ }^{16}$ Therefore, for Cohen, the manifold of sensation existing independently of pure thought is substituted for the methodological progression of science and a genetic theory of knowledge. independent of empirical consciousness. In contrast to the ephemeral nature of senseexperience, Cohen claims that philosophy "requires the presupposition of the eternal as opposed to the transitoriness of the earthly institutions and human ideas" ${ }^{17}$ In light of this, it can be said that Cohen subordinates being and existence to thought in order to safeguard the certainty and continuity of knowledge against the transitory nature of sensibility and experience. For Cohen being is primarily the being of thinking and this is what distinguishes his form of logical idealism from what he understood as the logic of being characteristic of subject-oriented forms of idealism that include both Helmholtz and Lange.

Cohen's most significant break with Kant is his conception of pure thought, which is based on the rejection of Kant's dualistic claim that knowledge has its origin in both the active faculty of the understanding, on one side, and the passive faculty of sensibility that exists independently of the understanding, on the other. Cohen, therefore, rejects the independent mediating faculty of pure intuition. He is able to overcome the problems that this rejection introduces by incorporating what he calls the 'fact' of the pure mathematical science. By incorporating this 'fact' of pure mathematic science into his logical method, Cohen is able to subordinate sensibility to the understanding through an extension of the transcendental logic to the forms of sensible intuition. For Cohen, this is possible since space and time are conceived of merely as principles derived from the fact of science. Cohen's pure logical thought, then, becomes the basis for scientific experience in contradistinction to Kant's ultimately empiricist concept of experience, which is based upon the faculties of sensible intuition. While Kant was forced to posit a separation between experience and knowledge, Cohen is able to posit the continuity of knowledge and scientific experience. For Cohen the continuity occurs within pure thought itself through the dissolution of the Kantian distinction between sensibility and the understanding. The continuity that Cohen asserts, however, is only established through the purification of empirical experience, i.e. within scientific experience and the subordination of a posteriori experience to the logical structures of pure mathematical science. 


\section{Benjamin's Critique of Cohen's Logical Idealism}

16 How does Walter Benjamin relate to the neo-Kantian tradition? In the two texts I examine at length in this section - his fragment "On Perception" and his essay "The Program of the Coming Philosophy" - Benjamin problematizes the Kantian and neo-Kantian epistemological standpoint. Kant, Benjamin claims, began from a very narrow concept of experience:

As an experience of the world, it was of the lowest order. The very fact that Kant was able to commence his immense work under the constellation of the Enlightenment indicates that he undertook his work on the basis of an experience virtually reduced to a nadir, to a minimum of significance. Indeed, one can say that the very greatness of his work, his unique radicalism, presupposed an experience which had almost no intrinsic value and which could have attained its (we may say) sad significance only through its certainty. ${ }^{18}$

17 While it is true that, Kant, especially in the Prolegomena to Any Future Metaphysics that will be able to come forward as Science (1783), derived the principles of experience from natural science, particularly mathematical physics, he did not aim to make experience identical to the 'object realm' of science. Nevertheless, Kant did restrict the possible objects of experience to those of Euclidean geometry and Newtonian physics insofar as the experience that counted for Kant was a form of scientific experience. As I will show, the Kantian emphasis on an objective and certain form of scientific experience led to a separation between experience in the everyday sense of the word and pure knowledge.

In contrast to the Kantian non-identity of knowledge and experience, Benjamin locates a different trend amongst the neo-Kantians. Specifically he recognizes their attempt to provide a systematic unity of knowledge. Whether or not this is successful remains to be seen, but nevertheless it remains an important point of difference between Kant and neoKantianism. Neither the Marburg School, of which Cohen was a member, nor the SouthWest or Baden School were exclusively concerned with scientific knowledge, but were interested in aesthetics, religion and ethics - in the case of Cohen - and history and culture in the case of Heinrich Rickert. In light of this, it is essential to grasp the distinction between Kant and neo-Kantianism in Benjamin's critique. Therefore, I propose to evaluate Benjamin's critique of Kant and neo-Kantianism on the basis of the two-fold problem of experience he poses: "First of all, there was the question of the certainty of knowledge that is lasting, and, second, there was the question of the dignity [Dignität] of an experience that is ephemeral". ${ }^{19}$ For Benjamin, Kant was only able to give an answer to the first question since his aim was to secure the timeless validity and certainty of cognition. In regards to neo-Kantianism, in order to secure the integrity of cognition from the ephemeral nature of experience, their concepts had to be purified of any content taken from sensible perception. Thus, the price that neo-Kantianism paid for the dignity and integrity of its epistemological standpoint was the subordination of empirical experience to a transcendent conception of pure thought and a strictly logical method.

Before moving onto Benjamin's critique of neo-Kantianism, it is necessary to examine how his critique relates to Kant, and also how neo-Kantianism interprets Kantian philosophy. This will allow us to navigate Benjamin's apparent conflation of Kant and neo-Kantianism in the aforementioned texts. It is useful, in this regard, to briefly examine Benjamin's fragment "On Perception", written in 1917, which precedes the 1918 "Program". In this text, the conflation of the Kantian and neo-Kantian standpoints 
appears more pronounced. Benjamin appears to provide a justification for the necessity of the neo-Kantian approach to concept formation from within the standpoint of Kantian critical philosophy. In short, Benjamin appears to largely accept the neo-Kantian problematic in regards to conceptual realism, i.e. the view that concepts are mirror images or accurate reproductions of reality - a view that both Cohen and Rickert rejected. Thus, Benjamin accepts the necessity of a fundamental separation between empirical experience and pure knowledge. The necessity of this separation is found in Kant's aim to avoid the collapse of his metaphysical concept of pure knowledge into the concept of experience. Benjamin locates a specific meaning of metaphysics in the context of Kant's philosophy: "Kant produced a metaphysics of nature and in it described that part of the natural sciences which is pure - that which proceeds not from experience but simply from reason a priori". ${ }^{20}$ This conception of knowledge faced potential problems from two sides. On one side, there is the empiricist problem of collapsing sensibility into the understanding. As a result, knowledge becomes subjective; it is conceived of as a product of experience. On the other hand, there is the rationalist problem of a discontinuity between knowledge and experience. In order to avoid this problematic, as Benjamin states, Kant posited "the so-called material of sensation to express the separation of the forms of intuition from the categories". ${ }^{21}$ In doing so, Kant could ground the continuity of a posteriori experience and knowledge while retaining the necessary separation between pure knowledge and empirical experience. The separation was achieved through the forms of intuition in which, as Benjamin puts it, the material of sensation is "imperfectly absorbed". ${ }^{22}$

For Benjamin, however, despite the scrutiny that Kant gives to metaphysics qua pure cognition, the concept of experience does not undergo the same critical treatment. In light of this, Benjamin makes a fundamental distinction between the concept of experience [der Begriff der Erfahrung] and the cognition of experience [die Erkenntnis der Erfahrung] which, he claims, have often been conflated in both Kantian and pre-Kantian philosophy. Due to this conflation, the differences between the immediate natural concept of experience and the cognition of experience have become confused. In order to secure the continuity and give it the quality of being a possible object of cognition, cognition of experience must be unified at a level that exceeds transitory sense experience. Thus, as Benjamin claims, at this point we are talking about two different conceptual realms - one empirical or experiential, and the other conceptual.

What Benjamin terms the cognition of experience, operates at the level of pure scientific knowledge, not concrete experience. As Benjamin states, for Kant "experience as an object of cognition is the unified and continuous manifold of cognition". ${ }^{23}$ In other words, it is only in the form of abstract objective experience that experience as such can become a proper object of cognition in the Kantian sense. Thus, for Benjamin, the experience that counted for Kant was that which could be granted the status of objective validity, i.e. that form of experience that Benjamin terms scientific experience. Kant had to separate what he understands as pure experience from natural or empirical experience in order to secure it as a valid object of knowledge. Therefore, for Kant, cognition is, as Benjamin insisted above, the system of nature, but with the caveat that the system of nature is by no means merely what is intuited sensibly.

According to Benjamin, it is precisely on the discontinuity between cognition and experience that Kant distinguished himself from the pre-Enlightenment tradition. For Benjamin, the pre-Enlightenment or rationalist tradition had an exalted conception of 
experience, one that was close to God. As such, the possibility of a rationalist deduction of knowledge from a first principle, i.e. the absolute, or an empiricist deduction of knowledge from experience was deemed possible. For Benjamin, however, the concept of experience that characterized the Enlightenment had, by contrast, been "stripped of its proximity to God". ${ }^{24}$ In conceiving of God as remote from both nature and existence, the concept of experience had been implicitly transformed. For Benjamin, what Kant provided was the methodological grounds by which such an impoverished form of experience can become a valid object of knowledge, i.e. one that is objective and universal. In order to guarantee the certainty and objectivity of knowledge, an appeal to principles beyond mere experience is necessary. Thus a discontinuity between experience and pure cognition is introduced, and the Newtonian and Euclidean conceptions of space and time become the valid forms of pure sensible intuition. ${ }^{25}$ Implicit within Kant's theory of knowledge, therefore, is a restriction of the possible objects of experience to those presented through the forms of pure intuition, namely objects of Euclidean Geometry and Newtonian physics. Furthermore, the grounds upon which the knowledge of the object is established objectively prohibits the continuity between empirical consciousness and experience qua scientific experience. Genuine knowledge rests on transcendental consciousness, a pure epistemological consciousness stripped of any subjective character. Despite this separation between knowledge and experience, as Benjamin claims, Kant's transcendental consciousness is formed through an analogy with empirical consciousness. Objectively certain knowledge is produced in relation to an empirical consciousness whose experience is characterized by the impoverished experience available to it. This is Benjamin's crucial point: Kant objectifies the impoverished concept of experience - the only experience he sees as available to the empirical subject - in the transcendental subject. As such, the limited, impoverished concept of experience is hypostasized when it becomes the basis of the Kantian conception of pure knowledge.

In light of this, Benjamin appears to see some promise in the neo-Kantian dissolution of the distinction between intuition and the intellect, something he also mentions in the fragment "On Perception". With this, Benjamin claims, there is a reconfiguration of the concept of experience itself. Within the elimination of the distinction between the independent faculty of sensible intuition and the spontaneous faculty of the understanding is a point at which the subject-object logic of Kant's epistemology is undermined. The question is how far can Benjamin take this from within the standpoint of neo-Kantianism? In his critique, Benjamin makes clear that in the interest of establishing the continuity of experience, neo-Kantianism represented experience as the system of sciences. As Benjamin claims, the neo-Kantian "rectification" of Kant's separation of sensibility and understanding ends "in the extreme extension of the mechanical aspect of the relatively empty Enlightenment concept of experience". ${ }^{26}$ They remain within the Kantian conception of experience as scientific experience that could not absorb metaphysical experience any more than the material of sensation is absorbed by the forms of sensible intuition. Thus, at the precise point at which neo-Kantianism aims to move beyond the Kantian concept of experience, it remains tied to the Kantian theory of knowledge. Accordingly, for Benjamin, both Kant and neo-Kantianism remain tied to a concept of experience derived from an Enlightenment worldview that comes to occupy a mythical status in both philosophies. In their attempt to overcome the object nature of the thing-in-itself, both Kant and neo-Kantianism prioritize a concept of 
experience, and a subject of that experience, which is discontinuous with experience in the everyday sense of the word.

By beginning from the 'fact of science', reality is absorbed into pure thought as the object realm to which the methods of pure mathematical science are applied. ${ }^{27}$ Knowledge becomes objective through its subordination to a transcendental logic distinct from empirical reality and a posteriori experience. But while Kant was forced to posit a separation between experience and knowledge, Cohen is able to posit the continuity of knowledge and scientific experience. For Cohen the continuity occurs within pure thought itself through the dissolution of the Kantian distinction between sensibility and the understanding. Thus, Cohen achieves what Kant could not within his separation between the faculties of sensibility and understanding. The continuity Cohen establishes, however, is only established through the purification of empirical experience, i.e. within scientific experience and the subordination of a posteriori experience to the logical structures of pure mathematical science.

Therefore, the solution offered by the neo-Kantians to Kant's separation of knowledge and experience exacerbates the problem for Benjamin. Neo-Kantianism extends the mechanical concept of experience that Benjamin found so problematic in the first place. Further, the mythical separation between subject and object that Kant presupposed becomes the foundation of neo-Kantian epistemology. The given reality of perception the empirical world - is conceived as an object of knowledge upon which the methods of natural science are continually and progressively converging. The objects that constitute that world are meaningful only insofar as they are objects of, or perhaps better yet, objects for knowledge. As Peter Fenves claims, within this mechanical concept of experience "there is no object of experience, for objects mean nothing". ${ }^{28}$ For Benjamin, neo-Kantianism had to reject sense experience in order to secure the continuity of pure scientific knowledge. Cohen's neo-Kantianism pushes the Kantian scientific worldview to its limit by absorbing empirical reality into pure thought; the object of scientific knowledge is thus not a concrete phenomenal thing, but a purely conceptual idea that exists in total separation from the world of perception and experience. The systematic continuum of knowledge and experience is achieved at the level of scientific knowledge through the extension of a form of transcendental logic. Thus, neo-Kantianism is systematic in a way that Kantian philosophy could not be; but it only achieves its systematicity by subordinating all forms of experience to its pure logic based on the principles of mathematical and natural science. In opposition to the Kantian separation of knowledge and experience, Cohen provides the foundation of the systematic continuity and unity of knowledge through the absolutisation of a genetic conception of pure logical thought.

27 It is from this perspective that Benjamin claims experience has been reduced to something meaningless, insignificant and without value for neo-Kantianism. Experience only becomes significant when it is objectified and subordinated to meta-empirical scientific principles or, as Benjamin states, "through its certainty". ${ }^{29}$ Science requires an object, an object moreover that is objective and certain. For experience to become such an object, its timeless validity must be secured. As objects of scientific inquiry, experience and the objects of experience are conceived of as meaningful and significant only insofar as they can be understood as valid objects of knowledge; experience itself is only continuous and certain insofar as it becomes objectified as scientific experience. Thus, while Benjamin concurs with the neo-Kantian demand for a continuity of experience and 
knowledge, he disputes the mathematical and scientific foundation of their epistemology that prioritizes abstract scientific experience and posits the unity of subject and object of experience within pure logical thought. Such a standpoint creates an unbridgeable gulf between the experiencing subject and the object of experience while, at the same time, stripping objects of their individual significance and meaning.

\section{Conclusion}

The twin aims of Benjamin's text become quite clear when counter-posed with Cohen's logical idealism: firstly, establishing the possibility of the continuity of knowledge and experience from the standpoint of concrete empirical experience; secondly, the overcoming of the mythic separation of subject and object that Benjamin views as present in both Kant's philosophy and neo-Kantianism. As Benjamin states:

The task of future epistemology is to find for knowledge a sphere of total neutrality in regard to the concepts of both subject and object; in other words to discover the autonomous, innate sphere of knowledge in which this concept no longer continues to designate the relation between two metaphysical entities. ${ }^{30}$

In order to overcome the mechanistic and abstract categories of neo-Kantianism, Benjamin proposes a revision of the Kantian categories founded upon or connected to what he refers to as primal concepts [Urbegriffe]. With its mathematical and logical ontology, neo-Kantianism had extended the Aristotelian categories of Kant's transcendental logic that are, for Benjamin, "both arbitrarily posed and exploited in a very one-sided way by Kant in the light of mechanical experience". ${ }^{31}$ With a new theory of orders, Benjamin claims to be able to expand the possible areas of experience to include those areas that Kant was unable to systematize..$^{32}$ While systematic in his intent, the categories of Benjamin's theory of knowledge would not be imposed externally onto experience from the standpoint of a timelessly valid scientific knowledge. Rather, the theory of knowledge itself must be expanded to include a form of experience that Benjamin calls "multiply gradated" and "nonmechanical". ${ }^{33}$

Benjamin highlights a tension between the Kantian claim that the concepts must be connected to a form of subjective intuition and the neo-Kantian claim that nonrepresentational concepts exists prior to reality in the form of transcendent logical structures. Benjamin's new theory of orders must be able to overcome this tension by both providing a sphere of pure knowledge from which concepts can be derived while, at the same time, providing continuity between experience and the concepts that structure experience. Benjamin aims to provide the foundation for a theory of knowledge that remains within the spirit of Kantian philosophy without imposing the limitations of knowledge qua scientific experience. In revising the Kantian theory of knowledge and experience, Benjamin is able to expand the sphere of possible experiences without reducing the object of experience to an object for a specific type of experience.

Benjamin's critique of neo-Kantianism is, perhaps, more satisfying than his proposed solution, which is underdeveloped in the two texts I examined here. However, perhaps it is not surprising that, in this context, Benjamin points to the figure of Johann Georg Hamann and, moreover, that after his engagement with neo-Kantianism he turned to the Romantic theory of reflection. (After all, the notion of an immanent absolute stands in stark contrast to Cohen's philosophy.) While I have noted disagreements between Cohen 
and Lange, they share the notion that the ideal, the concept or the Absolute are in opposition to existing reality. As Cohen writes in his Religion of Reason:

Messianism degrades and despises and destroys the present actuality, in order to put in the place of this sensible actuality a new kind of supersensible actuality, not supernatural, but of the future. The future creates a new earth and a new heaven and, consequently, a new actuality. ${ }^{34}$

In positing a gulf between a temporally specific experience of either past or present and a fulfilled experience deferred into the messianic future, Cohen forecloses any possibility of a metaphysically expanded concept of experience and denies the possibility of an immanent continuity between knowledge and existence. Cohen, therefore, juxtaposes two realms of experience - the eternal present of finite and immediate sensuous experience, and the paradoxical eternal novelty of an authentic experience posited in the messianic future. This, however, rests on the presupposition of the temporally specific conception of sense experience as something devoid of significance and meaning. The messianic future resides within the domain of universal history; the progressive universal development towards an eternal idea, an idea that remains absolutely discontinuous with the earthly sensuous actuality and activity of human beings. In its nihilistic rejection of reality, Cohen's neo-Kantianism lacks any force on the present. It is unsurprising, therefore, that Benjamin turns to Romanticism and its notion of an immanent absolute for a potential alternative to the problem of modern experience, i.e. the absence of the Absolute, totality, and unity.

\section{BIBLIOGRAPHY}

BENJAMIN, Walter, “On Perception”, in: Selected Writings 1, 1913-1926, eds. Marcus Bullock \& Michael W. Jennings (Cambridge, MA: Belknap Press of Harvard University Press, 1996), pp. 93-96. BENJAMIN, Walter, “On the Program of the Coming Philosophy”, in: Selected Writings 1, 1913-1926, eds. Marcus Bullock \& Michael W. Jennings (Cambridge: Belknap Press of Harvard University Press, 1996), pp. 100-110.

BENJAMIN, Walter, "Review of Richard Hönigswald's Philosophie und Sprache", in: Selected Writings 4, 1938-1940, eds. Howard Eiland \& Michael W. Jennings (Cambridge, MA: Belknap Press of Harvard University Press, 2003), pp. 139-144.

BÜCHNER, Ludwig, Last Words on Materialism and Kindred Subjects, trans. Joseph

McCabe (London: Watts \& Co., 1901).

COHEN, Hermann, Das Prinzip der Infinitesimal-Methode and seine Geschichte: Ein Kapitel zur Grundlegung der Erkenntniskritik (Berlin: Dümmler, 1883).

COHEN, Hermann, Religion of Reason: Out of the Sources of Judaism, trans. Simon Kaplan. (Oxford: Oxford University Press, 1995).

FENVES, Peter, The Messianic Reduction: Walter Benjamin and the Shape of Time. (Stanford: Stanford University Press, 2010). 
VON HELMHOLTZ, Hermann, Popular Lectures on Scientific Subjects, trans. E. Atkinson (London: Longmans, Green, and Co., 1881).

KÖHNKNE, Klaus Christian, The Rise of neo-Kantianism, trans. R. J. Hollingdale (Cambridge: Cambridge University Press, 1991).

LANGE, Fredrich Albert, History of Materialism and Critique of its Present Importance: Volume 2, trans. Ernest Chester Thomas (London: Routledge, 2001).

POMA, Andrea, The Critical Philosophy of Hermann Cohen, trans. John Denton (Albany: SUNY Press, 1997).

ROSE, Gillian, Hegel Contra Sociology (London: Verso, 2009).

WAHL, Reiner, "Identity and Correlation in Hermann Cohen's System of Philosophy", in: Hermann Cohen's Critical Idealism, ed. Reiner W. Munk (Amsterdam: Springer, 2006).

\section{ENDNOTES}

1. Walter Benjamin, "On the Program of the Coming Philosophy", in: Selected Writings 1, 1913-1926, eds. Marcus Bullock and Michael W. Jennings (Cambridge, MA: Belknap Press of Harvard University Press, 1996), p. 101.

2. Ludwig Büchner, Last Words on Materialism and Kindred Subjects, trans. Joseph McCabe (London: Watts \& Co., 1901), p. 279.

3. Hermann von Helmholtz, Popular Lectures on Scientific Subjects, trans. E. Atkinson (London: Longmans, Green, and Co., 1881), p. 45.

4. Cf. Fredrich Albert Lange, History of Materialism and Critique of its Present Importance: Volume 2, trans. Ernest Chester Thomas (London: Routledge, 2001), p. 218.

5. Cf. ibid, p. 165.

6. Cf. ibid. p. $344 / 345$.

7. Ibid, p. 346.

8. Klaus Christian Köhnke, TheRrise of neo-Kantianism, trans. R.J. Hollingdale (Cambridge: Cambridge University Press, 1991), p. 190-91.

9. Ibid, p. 194.

10. Hermann Cohen, Religion of Reason: Out of the Sources of Judaism, trans. Simon Kaplan (Oxford: Oxford University Press, 1995), p. 6.

11. For a discussion of this issue, see: Gillian Rose, Hegel Contra Sociology (London: Verso, 2009), p. 11; see also: Andrea Poma, The Critical Philosophy of Hermann Cohen, trans. John Denton (Albany: SUNY Press, 1997), p. 36. For Poma, Cohen's emphasis on the un-derivable nature of ideas reveals that Cohen's idealism is more indebted to a Platonic theory of ideas than a Kantian notion of a priori synthesis.

12. Poma, "The Critical Philosophy of Hermann Cohen", p. 58.

13. For example, in grounding his logic within ethics rather than the other way around, Cohen argues that Fichte commits an error typical of a logic of being. Crucially, for Cohen, ethics can only achieve an objective grounding if it recognizes and is subordinated to the primacy of logic qua pure thought.

14. Poma, "The Critical Philosophy of Hermann Cohen", p. 92.

15. Reiner Wahl puts this succinctly: "it is the movement of pure thought, which produces its thoughts from itself, to verify them as pure knowledge. The one and the other go together in this process of thought: the production of pure thought - not from pre-existing data, but from itself and the verification of this thought as pure knowledge." (Rainer Wahl, "Identity and Correlation 
in Hermann Cohen's System of Philosophy", in: Hermann Cohen's Critical Idealism, ed. Reinier W. Munk [Amsterdam: Springer, 2006], p. 85-6.)

16. Cf. Michael Friedman, A Parting of the Ways (Chicago: Open Court, 2000), p. 31.

17. Cohen, "Religion of Reason", p. 83.

18. Benjamin, "On the Programme of the Coming Philosophy", p. 101.

19. Ibid.

20. Benjamin, “On Perception", p. 93.

21. Ibid, p. 94.

22. Ibid.

23. Ibid, p. 95 .

24. Ibid.

25. Ibid, p. 94.

26. Benjamin, "On the Programme of the Coming Philosophy", p. 105.

27. Cf. Hermann Cohen, Das Prinzip der Infinitesimal-Methode and seine Geschichte: Ein Kapitel zur Grundlegung der Erkenntniskritik (Berlin: Dümmler, 1883), p. 119-20.

28. Peter Fenves, The Messianic Reduction: Walter Benjamin and the Shape of Time. (Stanford: Stanford University Press, 2010), p. 166.

29. A link between neo-Kantianism and positivism can be perceived in such a concept of knowledge. This is the claim Benjamin makes in a review of the neo-Kantian Richard Hönigswald's Philosophie und Sprache, written between 1938 and 1939: "the weakness of neoKantianism lies in its unconscious complicity with positivism - a complicity which it has always denied." The dominance of neo-Kantianism in Germany resulted in the loss of "critical and imaginative energies" which was echoed in the complicity and adaptation of neo-Kantian philosophy to the "established order". For Benjamin, from Natorp through to Cassier and Hönigswald, the critical energy of the early neo-Kantianism had been replaced by a dogmatic belief in the progress of science, and "the transcendental questioning had gradually been transformed into a ceremony no longer animated by any real intellectual effort." (Walter Benjamin, "Review of Richard Hönigswald's Philosophie und Sprache", in: Selected Writings 4, 1938-1940, eds. Marcus Bullock \& Michael W. Jennings [Cambridge, MA: Belknap Press of Harvard University Press, 2006], p. 140.)

30. Benjamin, "On the Programme of the Coming Philosophy", p. 104.

31. Ibid, p. 106.

32. Benjamin names art, jurisprudence and history as forms of this experience, but also includes the scientific forms of experience, such as biology, that Kant ignored because, as forms of empirical science, they did not meet the Kantian standard of apodictic certainty and objective validity.

33. Benjamin, "On the Programme of the Coming Philosophy", p. 107.

34. Cohen, Religion of Reason, p. 291.

\section{ABSTRACTS}

This article aims to examine the relationship between Walter Benjamin and neo-Kantianism, particularly Herman Cohen's logical idealism. I divide the article into two major sections: first, I examine the development of Cohen's philosophy and its relationship to Hermann von Helmholtz and Friedrich Albert Lange's early neo-Kantianism; second, I examine Benjamin's critique of Cohen. I focus specifically on two of Benjamin's early philosophical works - the fragment "On Perception" and the text "On the Program of the Coming Philosophy". Further, I aim to show how Benjamin attempts to disentangle neo-Kantianism from Kant's own philosophy. In doing so, 
Benjamin points to an alternative from within the tradition of Kantian and post-Kantian philosophy.

INDEX

Keywords: Benjamin Walter, Cohen Hermann, Kant Immanuel, neo-Kantianism, epistemology 